\title{
Squamous Cell Carcinoma of Lung in a Young Female Patient with Myasthenia Gravis
}

\author{
Abdolali Shahrasbi ${ }^{1 *}$, Mandana Mirzaei ${ }^{2}$, Delaram Amiri², Binazir Borukhian ${ }^{2}$ and \\ Zahra Mahboubi ${ }^{2}$ \\ ${ }^{1}$ Oncology Ward, Bouali Hospital, Tehran Medical Sciences, Islamic Azad University, Tehran, Iran \\ ${ }^{2}$ Bouali Hospital, Tehran Medical Sciences, Islamic Azad University, Tehran, Iran
}

*Corresponding author: Abdolali Shahrasbi, Oncology Ward, Bouali Hospital, Tehran Medical Sciences, Islamic Azad University, Tehran, Iran

\begin{tabular}{l}
\hline ARTICLE INFO \\
Received: 幽 July 07, 2019 \\
Published: 櫘 July 11, 2019 \\
\hline
\end{tabular}

Citation: Abdolali Shahrasbi, Mandana Mirzaei, Delaram Amiri, Binazir Borukhian, Zahra Mahboubi. Squamous Cell Carcinoma of Lung in a Young Female Patient with Myasthenia Gravis. Biomed J Sci \& Tech Res 19(3)-2019. BJSTR. MS.ID.003319.

\begin{abstract}
Lung cancer incidence is increased among the younger population, and various factors are being responsible for that [1,2]. Accompaniment of myasthenia gravis with solid tumors like lung cancer is reported [3,4]. A 28 year old housewife with persistent cough and exertional shortness of breath diagnosed with squamous cell carcinoma, she also has a history of seropositive myasthenia gravis, diagnosed 12 years ago, with right sided petosis, hoarseness and dysphagia. It seems that a history of thymoma increases the chance of extra thymic malignancies [3-5]. Occurrence of cancer in these patients might be synchronous or a few years before or after the onset of MG. Long-term exposure to corticosteroids and the 12-year history of MG are seemingly the leading causes of cancer development in this young female.
\end{abstract}

Keywords: Lung Squamous Cell Carcinoma; Young Adult Female; Myasthenia Gravis

\section{Introduction}

Lung cancer incidence is increased with the process of ageing and numerous factors are involved in the pathogenesis of this disease. on the other hand, it is becoming more prevalent among the younger population, with various factors such as gene mutatations, a history of pulmonary disease, a family history of cancer and dysregulation of the immune system, being responsible for that $[1,2]$. Accompaniment of myasthenia gravis with solid tumors like lung cancer is reported in a number of studies [3,4]. Here, we present a case of 28-year-old, non-smoker, female with squamous cell carcinoma of lung and a 12 year history of myasthenia gravis.

\section{Case Presentation}

A 28-year-old housewife is referred to the oncology clinic with the chief complaint of persistent cough and episodes of exertional shortness of breath. The patient also complains of a chest discomfort and a significant weight loss of $10 \mathrm{~kg}$ in the last two months. No complaints of hemoptysis are mentioned. She gives no history of environmental or occupational exposure and has never smoked in the past. The productive cough began 5 months prior to admission and has been treated with the diagnosis of pneumonia, due to lack of improvements, further investigation was conducted, leading to the diagnosis of a non-small cell lung cancer. Pathologic analysis revealed a non-small cell lung carcinoma, morphologically consistent with a squamous cell carcinoma, IHC staining results were positive for p63 and cytokeratin and negative for TIF1, NSE and synaptophysin markers, further confirming the diagnosis of SCC. The patient has a history of seropositive myasthenia gravis, diagnosed 12 years ago. MG manifested with right sided petosis, hoarseness and dysphagia, gradually causing involvement of other muscles.

Following the diagnosis, she has been medically treated with Mestinon, Cyclosporine and Prednisolone, and has underwent plasmapheresis and thymectomy. She has been on a maintenance dose of Prednisolone ever since. In the physical examination, the patient was hemodynamically stable and tachypneic. No signs of fever or hemoptysis were noted. In the chest auscultation, a diffuse fine crackle in both of the lungs and a stridor were heard. Chest retraction was also noted. The upper and lower limbs muscle force was $4 / 5$ and no signs of ptosis or proximal myopathy were observed. However, the patient had complaints of a generalized weakness. Chest CT reported bilateral multiple diffuse lung nodules, 
up to $9 \mathrm{~mm}$. CT scan of abdomen and pelvis showed no evidence of metastasis to the liver or adrenal glands and no retroperitoneal involvement was reported. The bone scan revealed lytic lesions on the posterior arch of the lower ribs (T-10, T-11, T-12). Complete blood count was significant for a leukocytosis with the majority of neutrophils and the metabolic panel showed an increase in the level of LDH and ESR. The rest of laboratory tests were unremarkable.

\section{Lab Test}

Following the diagnosis of SCC, the patient was put on a systemic chemotherapy treatment, and now, having received three sessions of treatment, the symptoms have decreased considerably (Tables $1 \& 2$ ).

Table 1.

\begin{tabular}{|c|c|}
\hline CBC & Result \\
\hline W.B.C (K/uL) & 14600 \\
\hline PMN (\%) & $87 \%$ \\
\hline LYM (\%) & $9 \%$ \\
\hline MONO (\%) & $1 \%$ \\
\hline EOS (\%) & $1 \%$ \\
\hline BASPPHIL (\%) & $0 \%$ \\
\hline R.B.C (K/uL) & 5.61 \\
\hline $\mathrm{Hb}(\mathrm{m} / \mathrm{uL})$ & 13.2 \\
\hline HCT (\%) & 41.5 \\
\hline MCV (FL) & 74.0 \\
\hline MCHC (g/dL) & 23.5 \\
\hline Platelet count (k/uL) & 300000 \\
\hline RDW (\%) & 17.3 \\
\hline LYM variant forms & - \\
\hline NRBC & - \\
\hline \multicolumn{2}{|l|}{ RBC morphology } \\
\hline Anisocytosis & - \\
\hline \multicolumn{2}{|l|}{ Microcytosis } \\
\hline Retic (\%) & Slightly \\
\hline 2.8 & \\
\hline
\end{tabular}

Table 2.

\begin{tabular}{|c|c|}
\hline Biochemistry & Result \\
\hline Urea $(\mathrm{mg} / \mathrm{dL})$ & 24.3 \\
\hline Creatinine $(\mathrm{mg} / \mathrm{dL})$ & 0.75 \\
\hline AST $(\mathrm{IU} / \mathrm{L})$ & 23.1 \\
\hline ALT $(\mathrm{IU} / \mathrm{L})$ & 30.4 \\
\hline ALP $(\mathrm{IU} / \mathrm{L})$ & 135 \\
\hline LDH $(\mathrm{IU} / \mathrm{L})$ & 850 \\
\hline BS $(\mathrm{mg} / \mathrm{dL})$ & 69 \\
\hline FE $(\mu \mathrm{g} / \mathrm{dL})$ & 35 \\
\hline TIBC $(\mu \mathrm{g} / \mathrm{dL})$ & 360 \\
\hline FE/TIBC & 10 \\
\hline Ferritin $(\mathrm{mg} / \mathrm{dL})$ & 120 \\
\hline
\end{tabular}

\section{Discussion}

Occurrence of lung cancer is associated with a variety of factors including smoking, indoor pollution (cooking fumes) or environmental exposure (heavy metals), a family history of lung cancer, hormonal agents, chronic pulmonary disease and viral infections of HPV and HIV $[2,6,7]$. The most prevalent type of lung cancer among the young female population is adenocarcinoma of the lung, which is commonly diagnosed at the stages III and IV, in the upper lobes, with a PS of 0-1 and among the lower socioeconomic classes [8-9]. In this case, a young, active, low income, housewife with no history of smoking, exposure to irritants or remarkable family history is diagnosed with stage IV, bilateral SCC of lung with bone metastasis. Myasthenia gravis is an autoimmune disease, starting in the 20 s and 30 s and most common among the women. This neuromuscular Junction defect is caused by the excessive production of autoantibodies to postsynaptic acetylcholine receptors and it is categorised as seropositive and seronegative. Symptoms often start with diplopia, spreading to the rest of the muscles. Association of MG with various types of diseases, such as autoimmune disorders, thymoma, hematologic malignancies and solid tumors like lung cancer is reported $[3,4,8]$. It seems that a history of thymoma increases the chance of extra thymic malignancies. Occurrence of cancer in these patients might be synchronous or a few years before or after the onset of MG; however, the most usual time of onset is either simultaneously with or one year after the diagnosis of MG $[3,4,10]$.

In this case the patient has a 12-year history of MG, who has been on a medical treatment with Prednisolone, Mestinon and Cyclosporine and has underwent plasmapheresis and thymectomy. As we know, corticosteroids suppress the immune system, the suppression is mainly restricted to the cellular immunity and has a less significant impact on the humoral immune system [10]. Our patient has a 12-year history of maintenance corticosteroid therapy, the subsequent immune dysregulation, might be responsible for the development of cancer in this young patient [11-15].

\section{Conclusion}

In this study, a young housewife with a history of MG for 12 years, who has undergone thymectomy and has a history of longterm corticosteroids therapy, has come up with non-small cell lung cancer, SCC type [16-19]. Apart from the history of MG and the long-term corticosteroid therapy, no other specific predisposing factors are found. Long-term exposure to corticosteroids and the 12-year history of MG are seemingly the leading causes of cancer development in this young female.

\section{References}

1. Eldrige L (2014) Lung cancer in young adults. Lung cancer foundation.

2. M Samet J, Avila Tang E, Boffetta P, M Hannan L ,Olivo Maston S, et al. (2009) Lung cancer in never smokers: clinical epidemiology and environmental risk factors. Clinical cancer research 15(18): 5626-5645. 
3. Levin N, Abramsky O, Lossos A, Karussis D, Siegal T, et al. (2005) Extrathymic malignancies in patients with Myasthenia gravis. Journal of the neurological sciences 237(1): 39-43.

4. Papatestas A, Osserman K, Kark A (1971) The relationship between thymus and oncogenesis: A study of the incidence of non thymic malignancy in myasthenia gravis. British journal of cancer 25(4): 635645.

5. Weksler B, S Nason K, Mackey D, Gallagher A, Pannathur A (2012) Thymoma and extrathymic cancers. The annals of thoracic surgery 93(3): 884-889.

6. Kitamura J, Takahashi Y, Neri S, Tommi K, Katakami N (2013) Lung squamous cell carcinoma in young female never smoker. Annals of thoracic and cardiovascular surgery 20: 589-591.

7. Lienert T, Serke M, Schonfeld N, Loddenkemper R (2000) Lung cancer in young females. European respiratory journal 16(5): 986-990.

8. Rich A, Khakwani A, Free C, Tata L, Stanley R, et al. (2015) Non smal cell lung cancer in young adults: presentation and survival in the English National Lung Cancer Audit. An international journal of medicine 108(11): 891-897.

9. Thomas A, Chen Y, Yu T, Jakopovic M, Giaccone G (2015) Trends and characteristics of young non small cell lung cancer patients in the united states. Frontiers in oncology 5: 113.

10. Sakamaki Y, Yoon H, Oda N (2006) Non small cell lung cancer associated with non thymomatous myasthenia gravis. The japanese journal of thoracic and cardiovascular surgery 54(5): 207-211.

11. Fedor ME, Rubinstein A (2006) Effects of long-term low dose corticosteroid therapy on humoral immunity. Annals of allergy asthma immunology 97(1): 113-116.

\section{ISSN: 2574-1241}

DOI: 10.26717/BJSTR.2019.19.003319

Abdolali Shahrasbi. Biomed J Sci \& Tech Res

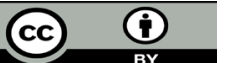

This work is licensed under Creative Commons Attribution 4.0 License

Submission Link: https://biomedres.us/submit-manuscript.php
12. Polo V, Zago G, Frega S, Canova F, Bonaldi L, et al. (2015) Non small cell lung cancer in a very young woman: A case report and critical review of the literature. American journal of case reports 16: 782-789.

13. Kozielski J, Kaczmarczyk G, Porebska I, Szmgin K, Gotecki M (2012) Lung cancer in patients under the age of 40 years. Contemporary oncology (Pozn) 16(5): 413-415.

14. Niimi K, Nagata E, Murata N, Sato M, Tanaka J, et al. (2015) Lung cancer associated with seronegative myasthenia gravis. Internal medicine 54(11): 1381-1384

15. Basta I, Pekmezovic T, Peric S, Nikolic A, Rakocevic Stojanovic V, et al. (2014) Extrathymic malignancies in a defined cohort of patients with myasthenia gravis. Journal of neurological sciences 346(1): 80-84.

16. Jaberi A, Manafi A, Movahhedan H, Zeighami M, Honarparvaran S (2012) The epidemiologic, clinical and laboratory findings of patients with myasthenia gravis in southern Iran. Galen medical journal 1(1): 20-23.

17. Hwan Lee J, Young Shin H, Min Kim S, Nam sunwoo I (2012) A case of lambert eaton myasthnic syndrome with small cell lung cancer and transient increase in antiacetylcholine receptor binding titer. journal of clinical neurology 8(4): 305-307.

18. Eivaz Mohammadi S, Gonzalez Ibarra F, Hekmatjou H, Mikkilineni R, Patel A, et al. (2014) Case report: Myasthenia gravis like syndrome presenting as a component of the paraneoplastic syndrome of lung adenocarcinoma in a nonsmoker. case reports in oncological medicine p. 5.

19. Shaygannejad V, Ghasemi M, Rajaee Z (2011) Myasthenia gravis as a presenting feature in a patient with lung cancer: A case report. Journal of Research in Medical Science 16(2): 229-232.

$\begin{array}{ll}\text { BIOMEDICAL } & \text { Assets of Publishing with us } \\ \text { RESEARCHES } & \text { - Global archiving of articles } \\ & \text { - Immediate, unrestricted online access } \\ \end{array}$

